\title{
IMMUNOLOGY IN BIOLOGICAL OCEANOGRAPHY AND MaRINE ECOLOGY
}

\author{
By B.B. Ward
}

\begin{abstract}
Immunology provides powerful methods to approach diverse research questions in biological and environmental sciences. Taking advantage of the endless variety of antibody molecules which the mammalian immune system can produce. immunoassays can be developed for almost any molecule. Antigen-antibody reactions can be visualized in many different ways, offering uniquely sensitive and specific assays. Whether used to identify morphologically indistinct larval forms or to quantify enzymes inside whole cells, immunological methods have wide applicability and versatility, currently unrealized in biological oceanography and marine ecology.
\end{abstract}

SEVERAL MAJOR QUESTIONS have driven research in biological oceanography for many years. Among them are: What is the magnitude and variability in marine primary production? What is the nature of biogeochemical cycling in the water column? What is the taxonomic diversity and relative abundance of planktonic populations (phytoplankton, bacteria and zooplankton)? While incremental progress is made continually, new knowledge results in the redefinition and reformulation of the questions. Thus the "answer" recedes as rapidly as we approach it.

Our continued focus on the same basic questions is indicative of the primitive state, for lack of a better term, of biological oceanography. We do not lack interesting and important questions, but we are "methods-limited." Our research material is dilute and distant, subject to motion and variability in three dimensions, and difficult and expensive to access. As a result, biological oceanographers must spend an extraordinary amount of effort developing new methods appropriate for oceanographic materials. In addition, oceanographers must be informed about and able to adapt methods developed in other fields.

Immunological methods emerged as powerful tools in clinical and basic medical research in the middle of this century (e.g., Coon et al., 1941: Campbell et al.. 1964; Axelson and Bock, 1972). Several decades later, they are being integrated into oceanographic "tool boxes." Immunology, like molecular biology, may do much more than refine

B.B. Ward, Marine Sciences Program. University of California, Santa Cruz, CA 95064 the answers to current research problems. They make it possible to attack questions that were previously unapproachable, and they will almost certainly open up new avenues of investigation and generate new questions as a result of the new kinds of information generated by the tools themselves. Immunology and molecular biology are fields outside of oceanography that have much to offer in the way of methods and new approaches. They are big tool boxes equipped with the latest in gadgets. Immunological tools are not applicable to every problem, just as not every seawater variable of interest can be measured with a CTD (conductivity, temperature and depth instrument). But increasing the size of our tool box can broaden the attack on familiar basic questions and open the door to new questions.

Immunological methods are designed to take advantage of some of the important features of the mammalian immune system. Simply put. mammalian immune systems recognize self and non-self molecules. Non-self molecules (called antigens) provoke an immune response, often in the form of antibodies. Antibody molecules are encoded by a family of genes which are transcribed and then spliced in sections that make possible almost unlimited variability in antibody structure. Each molecule includes both constant and variable regions. Antigen specificity is encoded in the variable region and the number of different antibody clones that the body can produce is effectively infinite. By recognizing and binding with its target antigen, each antibody acts as a specific defender of the body. To the biological or environmental researcher, the important thing is that antibodies can be raised in response to almost any 
foreign molecule. These antibodies can then be used as the basis of very specific and sensitive assays for that foreign molecule wherever it is found.

This note is intended not as a review of immunology or immunological applications but as an introduction for the uninitiated. with a brief review of examples of the approaches that are available. Methods and terminology concerned with several immunological techniques will be introduced. Then a few areas of oceanographic research for which immunological approaches hold special promise will be described. Several primers containing detailed protocols are available (e.g., Johnstone and Thorpe, 1987). Examples of application of immunology in aquatic research are included in the symposium volume edited by Yentsch et al. (1988).

\section{Why Immunology Can Provide Special Tools}

The attractiveness of immunological methods to environmental scientists lies largely in these two aspects, specificity and sensitivity. Specificity is limited only by the diversity of antigen and antibody molecules in nature. If two organisms or two cells or two drops of ooze each possess at least one unique antigenic determinant, then at least in theory, an immunoassay can be developed to distinguish the two. Sensitivity of immunoassays depends on the methods used to visualize the antigen-antibody reaction and can vary by orders of magnitude. In the most sensitive methods, some sort of amplification of the signal is employed, and detection limits on the order of nanomolar or picogram quantities are obtainable. Methods

Immunological detection methods can provide both qualitative and quantitative data. We can answer both "Is it there and how much?" The most obvious applications of immunological assays have to do with presence/absence of particular antigens or antigen-bearing cells. The same basic methods used to visualize the antigen-antibody reaction for preparative and qualitative assays can be used to develop quantitative assays for antigens. and likewise for antibodies.

In immunodiffusion and immunoelectrophoresis, the antigen-antibody reaction is visualized by virtue of the formation of an insoluble antigen-antibody complex in agarose gels (Ouchterlony and Nilsson. 1978). Gallagher et al. (1988) presented detailed descriptions of several agarose gel techniques applied to benthic ecology. These methods can be used for initial characterization of an antiserum as regards sensitivity, complexity and cross reactivity. Of the agarose gel methods, rocket immunoelectrophoresis can be most easily quantified and used to quantify dissolved antigen concentration (Feller and Ferguson, 1988; Korner and Zumft, 1989). Affinity chromatography and immunoprecipitation using solid supports have many useful applications: purification of serum to remove cross reactions or to increase homogeneity of a polyclonal antiserum; concentration of soluble antigens using immobilized antibody; fractionation

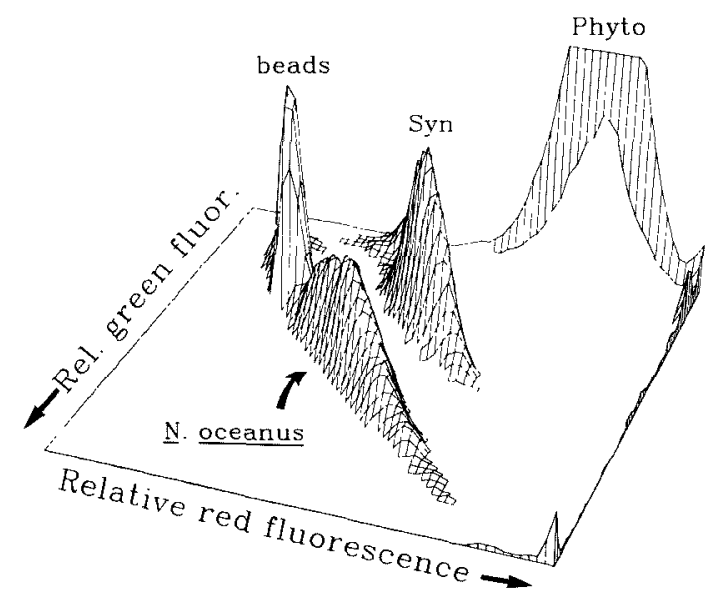

Fig. I: Flon' cytometric analysis of Nitrosococcus oceanus, a marine ammonium-oxidizing bacterium, diluted into coastal seaw'ater. Nitrosococcus cells were derived from pure culture and stained with a species-specific primary antibody (Ward and Carlucci, 1985) and a second antibody tagged with FITC. The X. $Y$ and $Z$ axes represent relative green fluorescence (515-630 nm. 3 decade log scale), relative red fluorescence $1660-700 \mathrm{~nm} .3$ decade log scale), and number of particles, respectively. The origin is in the upper left corner. Four distinct populations of particles can be seen: Synechococcus (Syn) cells with bright red fluorescence and some green fluorescence; Nitrosococcus cells with bright green fluorescence and less red fluorescence; larger phytoplankton (Phyto) with bright red fluorescence and no green fluorescence: $0.57 \mu \mathrm{m}$ beads (internal standard). Measurements were made using a Coulter EPICS $V$ flow cytometer with $488 \mathrm{~nm}$ argon laser excitation. (E.R. Zettler and R.J. Olson. Woods Hole Oceanographic Institution).

of immunoglobulin classes: separation of antigen bearing cells using immobilized antibody (Heyman et al. 1988). Separation of complex antigens using polyacrylamide gels, followed by immunological detection of the proteins on nitrocellulose of nylon supports (western blot), allows immunologically related proteins to be characterized by size (Towbin and Gordon, 1984). Western blotting is a sensitive method for detection of antigen in complex protein mixtures.

For identification and quantification of antibody in solution or in vivo, it is necessary to tag the molecule with a "reporter" molecule. Commonly used reporters involve linkage. either covalently or through a second antibody, with a radiolabel (radioimmunoassay; Chard, 1987), fluorochrome, colorigenic enzyme (enzyme-linked-immunosorbent assay; Voller et al., 1979), electron dense metal ions (e.g., immunogold) and magnetic beads (Lea et al.. 


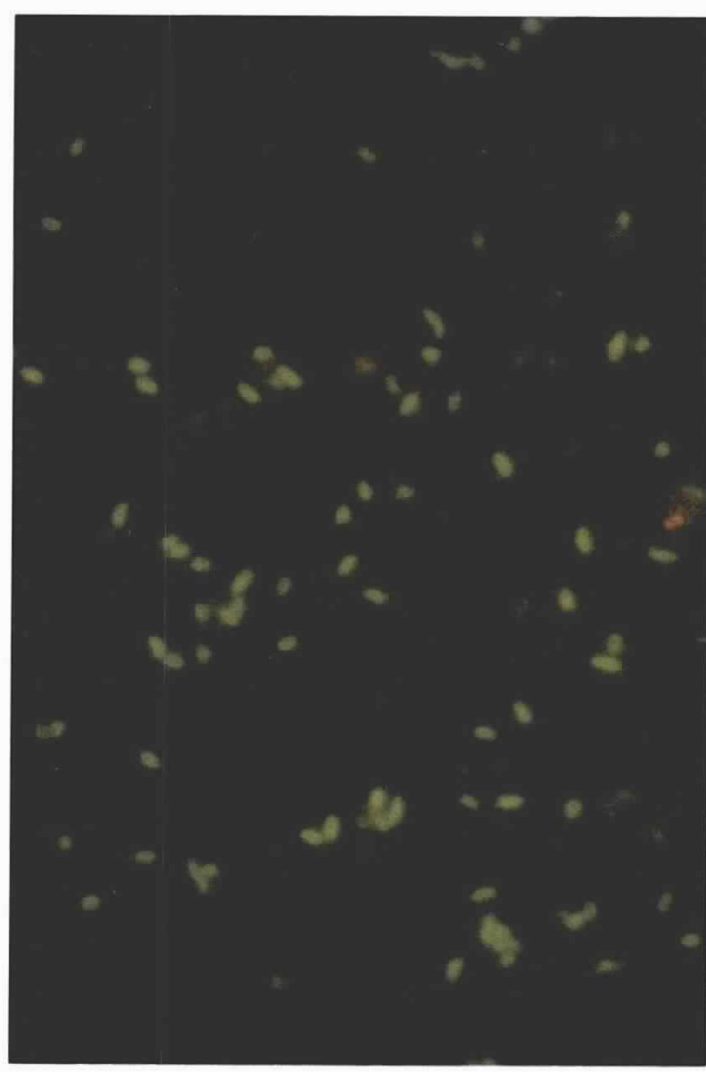

Fig. 2: Photomicrograph of the marine heterotrophic bacterium, Vibrio natriegens. Cells were formalin-fixed, permeabilized with lysozyme, and incubated with rabbit anti-nitrogenase antibodies, followed by fluorescein isothiocyanate (FITC)-conjugated goat anti-rabbit antibodies. Presence of nitrogenase containing cells is indicated by green fluorescence of FITC. The strain yields positive results both by acetylene reduction and by reacting with the antinitrogenase antibody. (C.A. Currin and H.W. Paerl, University of North Carolina, Institute of Marine Sciences).

1986). Detection methods then involve gamma or scintillation counting, epifluorescence microscopy, spectrophotometry or fluorometry, and electron microscopy. Sensitivities of the various detection methods vary widely depending on the actual protocols and mechanics of the assay. It is possible to mix and match the various reporters for truly creative assay methods; e.g., multiple fluorochromes at different wavelengths for epifluorescence microscopy or flow cytometry; radiolabeling for an internal enzyme and immunofluorescence for whole cells containing the enzyme detected using combined transmitted light and epifluorescence microscopy. Use your immagination!

Perhaps more so than for some methods, proper controls are essential for the application and interpretation of immunological methods. At present, poly- clonal sera (containing antibodies produced by many different immune cell clones, each antibody specific to the same antigen but perhaps recognizing different parts of the molecule and differing in specificity and affinity) are most commonly used in environmental applications. Inhomogeneity in antigens from different species (e.g., the same enzyme from different algal species) will result in variable sensitivity and reactivity by the polyclonal sera. This problem might be attenuated by use of an internal standard, a known antigen of known reactivity with the immunological reagents. False positives due to nonspecific (nonimmunological) reactions between antigen and antibody molecules can be caused by various chemical and physical conditions of the assay. Inclusion of negative and positive controls are therefore necessary.

\section{Examples}

It is one thing to understand the immune system, and another to exploit it for environmental science. One angle from which to assess the potential of immunological methods in oceanography is to consider the kinds of questions to which immunology can make a unique contribution.

Micoorganism species diversity: Organisms too small or too morphologically indistinct to be visually (including microscopically) identified can be tagged uniquely with specific antibodies and then identified by light, epifluorescent or electron microscopy. One of the first and still most common applications in oceanography is the use of species-specific antisera to enumerate picoplankton cells. Immunofluorescence is the method of choice because it allows visualization of individual cells using epifluorescent microscopy. Its recent uses in oceanography include identification and enumeration of many kinds of cells: nitrifying bacteria (Ward and Carlucci, 1985; Ward et al., 1989), heterotrophic bacteria (Dahle and Laake, 1982), picoplanktonic cyanobacteria and eukaryotic phytoplankton (Campbell et al., 1983; Shapiro and Campbell, 1988). Enumeration of immunofluorescently labeled cells by microscopy makes it possible to collect abundance data on a species-specific basis, which for many microorganisms was previously impossible. Due to the relative brilliance and specificity of immunoflourescent tags, it may be possible to combine immunofluorescence with automated detection systems, such as image processing and flow cytometry. The potential for flow cytometric analysis of immunofluorescently tagged bacteria in natural seawater is demonstrated in Fig. 1 (p. 31).

At present, most marine bacteria cannot be distinguished from each other, and the relative composition of natural assemblages is unknown. Similarly for planktonic stages of metazoans; while adult forms may be morphologically distinct, larvae often are not and their distribution and settling dynamics remain obscure. Using species-specific antisera, presence/ absence, distribution along chemical, geological, or physical gradients, community succession of indi- 
vidual microbial species can be studied. Speciesspecific probes for adults (which are morphologically distinct) may be applied to mixed populations of immature forms. One drawback to some of these applications is the necessity to culture or to collect unispecific biomass in order to produce antisera. It is an advantage, however, that it is often not necessary to know the function or physiological role of an antigen in order for it to be of use as a specific probe. Genetic probes offer comparable specificity and may eventually offer comparable sensitivity for this kind of question. The ability to identify and quantify the contribution of individual cell types to mixed microbial assemblages opens the door to investigations of species composition and diversity, succession and other ecological interactions in natural microbial assemblages.

Inducible enzymes: Many biologically mediated reactions are highly regulated in response to environmental factors. Examples of relevance to oceanographic problems, e.g., the marine nitrogen cycle, include uptake of nitrate by phytoplankton, the wellstudied nitrogen fixation system and the enzymes involved in bacterial denitrification. Balch et al. (1988) proposed an immunofluorescent assay for nitrate reductase to examine new production based on nitrate uptake in the presence of undetectable nitrate concentrations. Immunological probes for nitrogenase or dissimilatory nitrite reductase would allow us to determine which cells are expressing these oxygen-regulated enzymes, and thereby to study induction and environmental regulation of enzyme activity. Currin et al. (1990) used immunofluorescence to detect nitrogenase in free-living bacteria (Fig. 2), and were able to discriminate Nfixing bacterial cells from non-fixing cells in mixed cultures showing positive acetylene reduction activity. Gene probes for the genes encoding these enzymes could tell us the distribution of the genetic potential for these processes. Immunodetection of enzymes offers greater sensitivity than enzyme activity assays and does not depend on preservation of enzyme activity for detection. In situ enzyme activity is often not correlated with abundance of the protein. Thus immunological quantification of enzyme levels in combination with activity assays offers insights into enzyme regulation. In conjunction with gene probes, immunodetection allows us to study regulation of gene expression in natural systems. Gene expression and enzyme regulation are important factors in linking the presence of particular microorganisms to the biogeochemical processes which condition the chemical and biological environment of the ocean.

Symbiosis and chemical communication: In addition to quantitating individual cells, quantitative methods for subcellular antigens are also possible. Individual molecules can be used as tracers of metabolism or trophic interactions. Communications between host and symbiont may be mediated by chemical cues which may be immunologically iden-

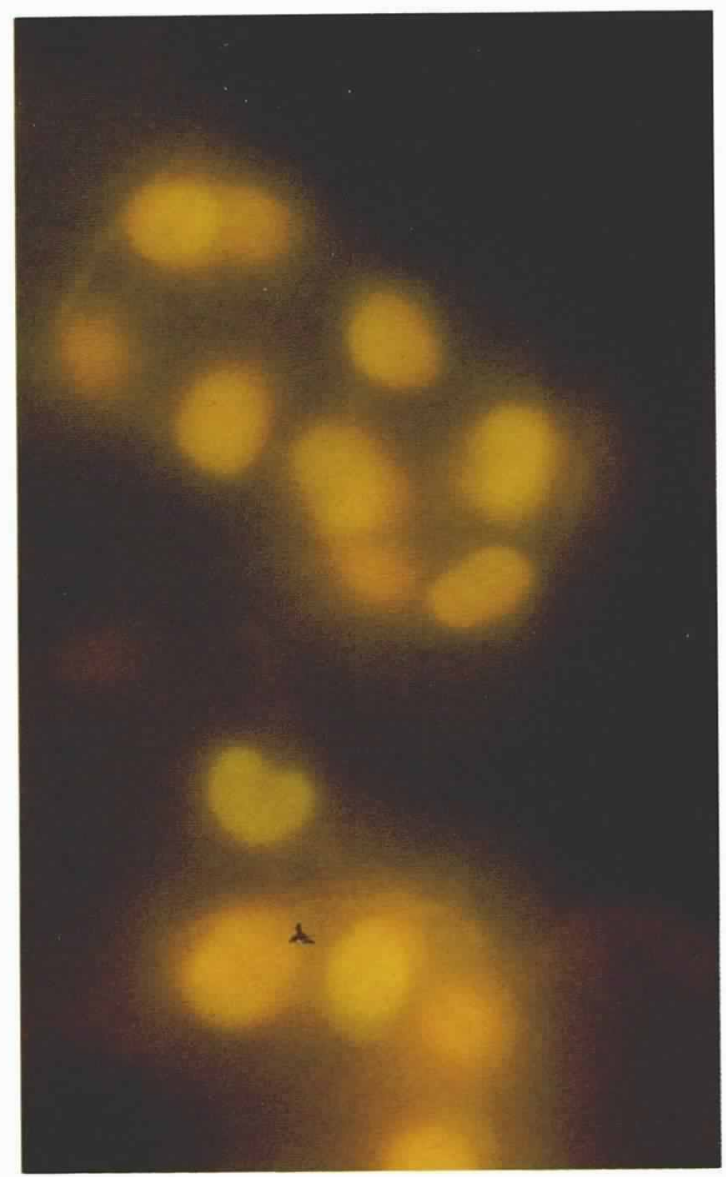

Fig. 3: Immunofluorescent microscope detection of RuBPCase in Thalassiosira weissflogii. Anti$R u B P C$ Case antibodies were raised in rabbits against enzyme isolated from Chaetoceros gracilis; the secondary antibody was goat anti-rabbit-FITC. The amount of RuBPCase in photosynthetic phytoplankton can be quantified by flow cytometry of immunofluorescently stained cells. (M.V.Orellana and M.J. Perry, University of Washington, School of Oceanography).

tified and localized. Environmental examples to date have used immunodetection to identify the presence of symbionts in host cells or tissue. Bergman (1988) used immunogold electron microscopy to localize nitrogenase in free-living and symbiotic cyanobacteria. Similarly, Cavanaugh et al. (1988) used protein A-gold to detect ribulose bisphosphate carboylase (RuBPCase) in bacterial symbionts of coastal bivalves.

Community ecology: For example, the contribution of various prey species to the diet of predators may be investigated if prey-specific antigens can be quantified in the gut of predators. Feller et al. (1979) used these methods to characterize a suite of antisera used for food web analysis in a soft bottom benthic community. Feller and Gallagher (1982) used immunological and electrophoretic techniques to detect 
Immunochemical

methods also offer

potential to speed up

some analysis and

quantitation steps. the presence of prey items in the gut of predators. Theilacker et al. (1986) developed an immunological assay for detection of anchovy egg protein in the gut of euphausiid predators.

Processes, rates and regulation: Immunochemical methods can be used to localize enzymes within cells (see above). If these enzymes are key in particular metabolic processes of geochemical significance. it may also be possible to link expression of the enzyme with the magnitude of the process or rate reaction (Fig. 3, p. 33). Using an immunofluorescent assay for RuBPCase, instead of simply localizing the occurrence of the enzyme in marine phytoplankton, Orellana et al. (1988) have correlated the level of enzyme with the photosynthetic capacity of phytoplankton (Fig. 3). In combination with flow cytometry, this approach should make it possible to develop a "single-cell immuno-photosynthetic probe" for field applications. Much research effort is currently being expended in the attempt to use ocean color data obtained by satellite to infer the magnitude of primary productivity around the globe. If photosynthetic capacity can be related to pigment content, the relationship between enzyme content and photosynthetic capacity is an important link in the interpretation of satellite data. Although not an immediate solution, this approach demonstrates the potential application of immunodetection to the big question of global primary productivity.

It is not possible to relate quantity of enzyme alone to the rate of the enzyme mediated reaction, but possibilities like ratios of two enzymes or relationships between enzymes and other chemical markers (e.g., pigments, inducer, substrate, etc.) may enhance the power of the approach. Immunodetection of subpopulations can be combined with metabolic measurements to yield species-specific rate information. For example, the combination of autoradiography with immunofluorescence to estimate autotrophic activity by nitrifying bacteria (Ward, 1984) or the sorting of tagged cells using flow cytometry and the measurement of nitrogen or carbon assimilation in the sorted subpopulation.

Microenvironments and small-scale variability: The suggestion that physical heterogeneity in the marine pelagic environment may allow the occurrence of biological reactions not compatible with bulk conditions is a popular notion. The disproportional importance of marine snow in terms of organic matter, phytoplankton and bacterial biomass is an outstanding example (Alldredge et al., 1986). That snow particles provide refugia for anaerobic metabolisms has been partially tested using microelectrodes to show that oxygen is seriously depleted within snow. Immunochemical probes for enzymes associated with particular metabolisms could be used to investigate whether the conditions in the microhabitat actually allow the survival of anaerobic microorganisms. Microelectrodes have been used to show localized oxygen depletion in cyanobacterial bundles implying that nitrogenase may be localized in re- sponse to oxygen tension within certain regions of cyanobacterial bundles in oxygenated waters (Pearl and Bebout, 1988). Antibodies specific for enzymes or pigments associated with archebacterial methanogens might be one way to test whether conventional methanogens are part of microenvironmental consortia in the surface ocean.

Species-specific probes would not be appropriate for these needs, because many of the organisms suspected to be involved have never been identified or cultured. However, because many important enzymes are highly conserved among evolutionarily distantly related organisms, probes developed from known species make powerful tools. The protein may be even more highly conserved than the DNA sequence encoding it due to functional constraints on the enzyme and the degeneracy of the genetic code.

Automation and rapid data acquisition: Rate of data acquisition remains a limitation for biological oceanography. While physical variables and many chemical variables can be rapidly and remotely sensed, distribution, abundance and identification of organisms still requires time-consuming and often tedious laboratory work, such as microscopy. Nothing can replace microscopy in many of the techniques described here, but immunochemical methods also offer potential to speed up some analysis and quantitation steps. Just as the unique autofluorescence signals of picoplankton have made possible automated analysis of picoplanktonic communities by flow cytometry (Chisholm et al.. 1988), immunological tags can do the same for cells in the same size range which are not naturally fluorescent.

\section{The Future}

There are many more examples of potential and realized applications of immunology in biological oceanography and ecology (cf. Yentsch et al., 1988). The methods are versatile and accessible, many not requiring exotic equipment or reagents. They are amenable to automated analysis and yield information currently not obtainable by other means. The use of immunological methods will undoubtedly expand in the future, as the techniques become more routine, simply another kind of tool in the tool box, and less obscure novelty items.

References

Alldredge, A.L.. J.J. Cole and D.A. Caron. 1986: Production of heterotrophic bacteria inhabiting macroscopic organic aggregates (marine show) from surface waters, Limmol. Oceanogr. 31. 68-78.

Axelson, N.H. and E. Bock, 1972: Identification and quantification of antigens and antibodies by means of quantitative immunoelectrophoresis. A survey of methods.I. Immunol. Meth., I, 109-121.

Balch, W.M. C.M. Yentsch, B. Reguera and W. Campbell. 1988: Examining nitrate reduction by phytoplankton with an immunoassay. In:Immunochemical Approachesto Coastal. Estuarine and Oceanographic Questions. Lecture Notes on Coastal and Estuarine Studies. C.M. Yentsch. F.C. Mague and P.K. Horan, eds., Springer-Verlag. 263-276.

Bergman, B.. 1988: Localization of nitrogenase in free-living and symbiotic cyanobacteria by immunocytochemistry. Eos. (abstract) 69(44), 1099. 
Campbell, L., E.J.Carpenter and V.J. Iacono. 1983: Identification and enumeration of marine chroococcoid cyanobacteria by immunofluorescence. Appl. Environ. Microbiol., 46. 553-559.

Campbell, D.H., J.S. Garvey, N.E. Cremer and D.H. Sussdorf, 1964: Methods of Immunology. W.A. Benjamin. Inc.. NY. $545 \mathrm{pp}$.

Cavanaugh. C.M.. M. Veenhuis and M.S. Abbott, 1988: Immunochemical localization of ribulose-1.5-bisphosphate carboxylase (RuBPCase) in the symbiont-containing gills of Atlantic coast bivalve, Solemva velum. Eos, (abstract), $69(44), 1099$

Chard, T., 1987: An introduction to radioimmunoassay and related techniques. In: Laboratory Techmiques in Biochemistry and Molecular Biology. vol. 6. part 2. 3e. T.S. Work. E. Work, eds., Elsevier, North Holland, Amsterdam, 274 pp.

Chisholm, S.W., R.J. Olson, E.R. Zeuler, R. Goerlicke, J.B. Waterbury and N.A. Welschmeyer, 1988: A novel freeliving prochlorophyte abundant in the oceanic euphotic zone, Nature. 334, 340-343.

Coons. H.A.. J.H. Creech and N.R. Jones, 1941: Immunological properties of an antibody containing a fluorescent group. Proc. Sor. Exptl. Biol. Med., 47, 200.

Currin. C.A., H.W. Paerl, G.K. Suba and R.S. Alberte, 1990: Immunofluorescence detection and characterization of $\mathrm{N}$, fixing microorganisms from aquatic environments. Limmol. Oceanogr.. 35, (in press)

Dahle. A.B. and M. Laake, 1982: Diversity dynamics of marine bacteria studied by immunofluorescent staining on membrane filters. Appl Environ. Microbiol 43, 169-176.

Feller, R.J., G.L. Taghon, E.D. Gallagher, G.E. Kenny and P.A. Jumars, 1979: Immunological methods for food web analysis in a soft-bottom community, Mar. Biol., 54, 61 74.

Feller, R.J. and E.D. Gallagher, 1982: Antigenic similarities among estuarine soft-bottom benthic taxa. Oecologia. 52 . 305-310.

Feller, R.J. and R.B. Ferguson, 1988: Quantifying stomach contents using immunoassays: A critique. In: Immunochentical Approaches to Coastal, Estuarine and Oceanographic Questions. Lecture Notes on Coastal and Estuarine Studies. C.M. Yentsch. F.C. Mague and P.K. Horan, eds, SpringerVerlag. 295-303.

Gallagher, E. D., P.A. Jumars and G.L. Taghon, 1988: The production of monospecific antisera to soft-bottom benthic taxa. In: Immunochemical Approaches to Coastal. Estuarine and Oceanographic Questions. Lecture Notes on Coastal and Estuarine Studies. C.M. Yentsch, F.C. Mague and P.K. Horan, eds., Springer-Verlag. 74-98.

Heyman. U., B. Heyman, and B.B. Ward, 1988: Cell affinity chromatography for a marine nitrifying bacterium. In Immunochemical Approaches to Coastal. Estuarine and Oceunographic Questions. Lecture Notes on Coastal and Estuarine Studies. C.M. Yentsch, F.C. Mague and P.K. Horan. eds.. Springer-Verlag. 100-116.
Johnstone, A and R. Thorpe, 1987: Immunochemistry in Practise. Blackwell Scientific Publications, Oxford, 306 pp.

Korner. H. and W.G. Zumft, 1989: Expression of denitrification enzymes in response to dissolved oxygen level and respiratory substrate in continuous culture of $P$ seudomonas stutzeri. Appl. Environ. Microbiol.. 55. 1670-1676.

Lea, T., E. Smeland, S. Funderud, F. Vartdal, C. Davies, K. Beiske and J. Ugelstad. 1986: Characterization of human mononuclear cells after positive selection with immunomagnetic particles, Scand. J. Immunol.. 23, 509.

Orellana, M.V.. M.J. Perry and B.A. Watson, 1988: Probes for assessing single cell primary production: antibodies against ribulose-1.5-bisphosphate carboxylase (RuBPCase) and Peridinin/Chlorophyll a protein (PCP). In: Immunochemical Approaches to Coastal, Estuarine and Oceanographic Questions. Lecture Notes on Coastal and Estuarine Studies. C.M. Yentsch. F.C. Mague and P.K. Horan, eds., Springer-Verlag, 243-262.

Ouchterlony, O. and L.A. Nilsson, 1978: Immunodiffusion and immunoelectrophoresis. In: Handbook of Experimental Immunology, 4E. section 32. D.M. Weir, L.A. Herzenberg and C. Blackwell, eds., Blackwell Scientific Publications. Oxford, 19.1-19.44.

Pearl, H.W. and B.M. Bebout, 1988: Direct measurement of O,depleted microzones in marine Oscillatoria: Relation to N, fixation. Science. 241, 442-445

Shapiro, L.P. and L. Campbell, 1988: Immunochemical characterization of the ultraphytoplankton. Eos, (abstract). 69(44). 1099

Theilacker, G.H., A.S. Kimball and J.S. Trimmer, 1986: Use of an ELISPOT immunoassay to detect euphausiid predation on larval anchovy. Mar. Ecol. Prog. Ser., 30, 127-131.

Towbin. H. and J. Gordon, 1984: Immunoblotting and dot immunobinding - Current status and outlook.J.Immunol. Meth., 73, 313 .

Voller. A., D.E. Bidwell and A. Bartlett, 1979: The Enzyme Linked Immunosorbent Assay. Dynatech Laboratories, Inc., Alexandria, $125 \mathrm{pp}$.

Ward. B.B.. 1984: Combined autoradiography and immunofluorescence for estimation of single cell activity by ammonium-oxidizing bacteria. Limnol. Oceanogr.. 29, $402-410$.

Ward, B.B. and A.F. Carlucci, 1985: Marine ammonia- and nitrite-oxidizing bacteria: Serological diversity determined by immunofluorescence in culture and in the environment. Appl. Environ. Microbiol., 50, 194-201.

Ward, B.B.. H.E. Glover and F. Lipschultz, 1989: Chemoautotrophic activity and nitrification in the oxygen minimum zone of Peru. Deep-Sea Res.. 36, 1031-1051.

Yentsch. C.M., F.C. Mague and P.K. Horan, eds., 1988: Immunnchemical Approaches to Coastal. Estuarine and Oceanographic Qucstions. Lecture Notes on Coastal and Estuarine Studies. Springer-Verlag. 399 pp. J 